Annals of Phlebology

Vol. 18, No. 3, December, 2020

Original Article

https://doi.org/10.37923/phle.2020.18.3.51

\title{
Body Mass Index of Patients with Nutcracker Syndrome
}

\author{
Division of Vascular Surgery, Department of Surgery, University of Ulsan College of Medicine and Asan Medical \\ Center, Seoul, Korea
}

Eunae Byun, M.D., Hyangkyoung Kim, M.D., Ph.D., Seunghee Park, R.N., Youngjin Han, M.D., Ph.D., Tae-Won Kwon, M.D., Ph.D., and Yong-Pil Cho, M.D., Ph.D.

\begin{abstract}
Objective: Low body mass index (BMI) is a risk factor for nutcracker syndrome (NCS). We evaluated the BMI and symptoms of patients having NCS.

Methods: This was a retrospective study of patients who were diagnosed with NCS between 2010 and 2015. The diagnosis was based on computed tomography, ultrasound, magnetic resonance venography, or intravascular ultrasonography findings. The BMI of these patients was compared with the BMI of an equal number of controls selected from our departmental database and matched for sex and age.

Results: A total of 30 patients were included in this study. There were 22 female patients $(73.3 \%)$ and 8 males $(26.7 \%)$ with a median age of 38.5 years (interquartile range [IQR], $26.75 \sim 56.25$ years). The median age of female patients was 42.0 years (IQR, 32.75 57 years) and that of male patients was 25.5 years (IQR, 19.25 48.75 years). The mean BMI was $20.2 \pm 2.7 \mathrm{~kg} / \mathrm{m}^{2}$ (range, $13.6 \sim 25.1 \mathrm{~kg} / \mathrm{m}^{2}$ ). The mean BMI of female patients was $20.5 \pm 2.7 \mathrm{~kg} / \mathrm{m}^{2}$ and that of male patients was $19.7 \pm 3.0 \mathrm{~kg} / \mathrm{m}^{2} \quad(\mathrm{p}=.482)$. The mean BMl of the matched cohort was $22.08 \pm 3.5 \mathrm{~kg} / \mathrm{m}^{2}$ $(p=.022)$. The most common symptom was gross hematuria (18 patients, $60.0 \%$ ). The other symptoms included abdominal pain $(17,56.7 \%)$, flank pain $(9,30.0 \%)$, pelvic symptoms including heaviness, fullness, and dysuria $(6,20.0 \%)$, and back pain $(1,3.3 \%)$.

Conclusion: The BMI of patients with NCS was significantly lower than that of the controls. NCS was more common in women, and the most common symptom was gross hematuria. (Ann Phlebology 2020;18:51-54)
\end{abstract}

Key Words: Nutcracker syndrome, Renal vein entrapment, Body mass index, Hematuria, Renal vein entrapment

Corresponding author: Hyangkyoung Kim, 88 Olympic-ro 43-gil, Songpa-gu, Seoul 05505, Korea, Division of Vascular Surgery, Department of Surgery, University of Ulsan College of Medicine and Asan Medical Center Tel: 02-3010-1587, Fax: 02-474-9027 E-mail: cindycrow7456@gmail.com

\section{INTRODUCTION}

Nutcracker syndrome (NCS) is a symptomatic vascular compression disorder that involves venous outflow obstruction due to compression of the left renal vein (LRV), most commonly between the aorta and the superior mesenteric artery (SMA), although variations exist. Unless the clinical situation is correlated with positive imaging findings for the diagnosis of NCS, it is referred to as the nutcracker phenomenon. The signs and symptoms of NCS are related to renal hypertension and range from objective signs, such as hematuria and proteinuria, to nonspecific symptoms, such as low back pain, pelvic discomfort, pelvic varicose veins, and atypical varicose veins in the lower limb $(1,2)$. The incidence and etiology of the condition are not entirely known. The narrow angle between the aorta and SMA or anatomic variations of the LRV are suggested as possible risk factors (3). Since NCS often occurs in lean patients, a low body mass index (BMI) was suspected as a risk factor for NCS. However, few studies have reported the BMI of adult patients with $\operatorname{NCS}(2,4)$. We aimed to evaluate the BMI of patients with NCS and their clinical manifestations.

\section{MATERIALS AND METHODS}

This was a retrospective study that included patients above 18 years of age diagnosed with NCS between 2010 and 2015. The diagnosis of NCS was based on ultrasound, computed tomography venography (CTV), magnetic resonance venography (MRV), venography, or intravascular ultrasonography (IVUS) findings. On ultrasound, the diagnostic criteria were ratio of the anteroposterior diameter of LRV at the hilum and at the aortomesenteric angle of $>5$ and a ratio of peak systolic velocity at the hilum and at the aortomesenteric angle $>5$. On CTV and MRV, the 
diagnostic criterion was the diametric ratio of the LRV between the hilum and the aortomesenteric angle greater than 5, similar to that for the US criteria. LRV occlusion with the development of collateral veins in the vicinity was also considered positive for NCS. If the computed tomography (CT) scan did not show the venous phase, the final diagnosis was made only when there was an additional imaging study. On venography, a venous pressure gradient of $\geq 3 \mathrm{mmHg}$ between the hilar LRV and the Inferior vena cava (IVC) was considered positive for diagnosis. IVUS was also used to measure the degree of venous stenosis (2).

Signs and symptoms correlated with the diagnosis of NCS, including hematuria, flank pain, and signs and symptoms related to the gonadal vein reflux, such as pelvic pain, fullness, heaviness, dysuria, and dyspareunia, were evaluated. BMI was reviewed for all patients.

The BMIs of the study subjects and an equal number of controls selected from the database of patients who underwent appendicectomy between and 2010 2015 were compared. The study subjects and controls were matched for sex and age using the $\mathrm{R}$ software version 3.2.4 ( $\mathrm{R}$ Development Core Team, 2006).

The frequency of symptoms related to NCS was reviewed. Quantitative and qualitative variables were summarized separately by descriptive statistics after normality testing (Kolmogorov-Smirnov test). For quantitative variables, an independent sample t-test or a Mann-Whitney $U$ test was used. The mean BMI and standard deviation of all patients included in the study were calculated. Mean BMI differences were compared between men and women and between two groups. Differences in the mean BMI were compared on the basis of the presence of symptoms. A $p$ value of $<.05$ was considered statistically significant. Statistical analyses were performed using SPSS version 21.0 (IBM Corp., Armonk, NY, USA).

\section{RESULTS}

A total of 30 patients were included in this study. The baseline characteristics, including age and BMI, are summarized in Table 1. There were 22 female patients $(73.3 \%)$ and 8 males $(26.7 \%)$ with a median age of 38.5 years (interquartile range (IQR, 26.75 56.25) years. The median age of females was 42.0 years (IQR, 32.75 57 years), and that of males was 25.5 (IQR, 19.25 48.75) years. The ratio of the mean diameter between the hilum and aortomesenteric angle was 5.75 \pm 0.41 (range, 5.20 6.20). The mean BMI was $20.2 \pm 2.7 \mathrm{~kg} / \mathrm{m}^{2}$ (range, $13.6 \sim$ $25.1 \mathrm{~kg} / \mathrm{m}^{2}$ ). The mean BMI of females was $20.5 \pm 2.7$ $\mathrm{kg} / \mathrm{m}^{2}$, and that of males was $19.7 \pm 3.0 \mathrm{~kg} / \mathrm{m}^{2}$ (Fig. 1, $\mathrm{p}=.482$ ).

Out of 4,380 patients from the appendicectomy database, the 30 patients were selected as the control group. The sex and age of the control group matched well with those of the NCS group (Table 1, $\mathrm{p}=.761$, and $\mathrm{p}=.790$, respectively). In the control group, the mean BMI of females was

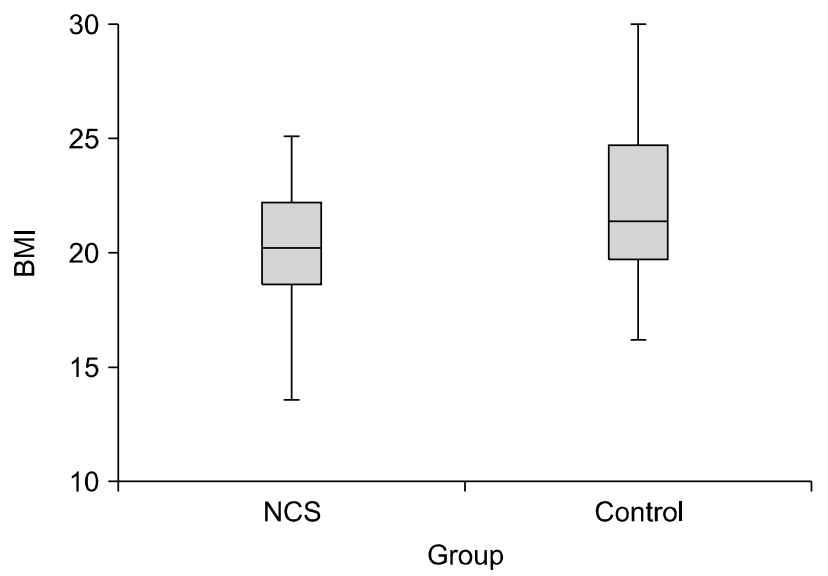

Fig. 1. The mean BMI of patients with NCS and controls $(p=.022)$. BMI: body mass index, NCS: nutcracker syndrome.

Table 1. Baseline characteristics

\begin{tabular}{lccrr}
\hline & Total & Male & Female & $\mathrm{p}$ \\
\hline Patients & & & & \\
$\mathrm{n}$ & 30 & $8(26.7 \%)$ & $22(73.3 \%)$ & $<0.001$ \\
Age & $38.5(\mathrm{IQR} 26.75 \sim 56.25)$ & $25.5(\mathrm{IQR} 19.25 \sim 48.75)$ & $25.5(\mathrm{IQR} 32.75 \sim 57)$ & 0.482 \\
BMI & $20.2 \pm 2.7$ & $19.7 \pm 3.0$ & $20.5 \pm 2.7$ & \\
Matched patients & 30 & $6(20.0 \%)$ & $24(80.0 \%)$ & 0.230 \\
n & $38.5(\mathrm{IQR} 31.5 \sim 55.25)$ & $25.5(\mathrm{IQR} 20.5 \sim 45.5)$ & $26.5(\mathrm{IQR} 30.5 \sim 46.75)$ & 0.065 \\
Age & $22.1 \pm 3.5$ & $24.4 \pm 2.9$ & $21.5 \pm 3.4$ & \\
BMI & & & &
\end{tabular}

IQR: interquartile range, BMI: body mass index. 
$21.5 \pm 3.4 \mathrm{~kg} / \mathrm{m}^{2}$ and that of males was $24.4 \pm 2.9 \mathrm{~kg} / \mathrm{m}^{2}$ $(\mathrm{p}=.065)$. The mean BMI of the control group was $22.1 \pm 3.5$ $\mathrm{kg} / \mathrm{m}^{2}$ (range, $16.1 \sim 30.2 \mathrm{~kg} / \mathrm{m}^{2}$ ), which was significantly higher than that of the NCS group $(p=.022)$.

The imaging modalities used for the diagnosis were as follows: duplex ultrasound in $3(10.0 \%)$, CTV in 29 (96.7\%), MRV in $3(10.0 \%)$, and venography in $2(6.7 \%)$ subjects.

The most common symptom was gross hematuria (18 patients, $60.0 \%$ ). The other symptoms were abdominal pain (17, 56.7\%), flank pain $(9,30.0 \%)$, pelvic discomfort including heaviness, fullness, and dysuria $(6,20.0 \%)$, and back pain $(1,3.3 \%)$. The mean BMI did not show a significant difference with the presence or absence of symptoms: hematuria $\left(19.8 \pm 2.9 \mathrm{~kg} / \mathrm{m}^{2}\right.$ vs $20.8 \pm 2.5 \mathrm{~kg} / \mathrm{m}^{2}$, $\mathrm{p}=.337)$, abdominal pain $\left(20.0 \pm 2.9 \mathrm{~kg} / \mathrm{m}^{2}\right.$ vs $20.5 \pm 2.5$ $\left.\mathrm{kg} / \mathrm{m}^{2}, \mathrm{p}=.635\right)$, flank pain $\left(20.3 \pm 2.4 \mathrm{~kg} / \mathrm{m}^{2}\right.$ vs $20.2 \pm 2.9$ $\left.\mathrm{kg} / \mathrm{m}^{2}, \mathrm{p}=.927\right)$, and pelvic symptoms $\left(20.9 \pm 1.9 \mathrm{~kg} / \mathrm{m}^{2}\right.$ vs $20.1 \pm 2.9 \mathrm{~kg} / \mathrm{m}^{2}, \mathrm{p}=.572$ ), respectively.

\section{DISCUSSION}

NCS, also known as left renal vein compression or renal vein entrapment syndrome, refers to the extrinsic narrowing of the LRV between the abdominal aorta and proximal SMA (5). There is a lack of consensus about the prevalence of the disease, partly because of an absence of definitive diagnostic criteria and partly because of the variability in symptomatic presentation (6). The prevalence of this condition is reported to be higher in females; however, it has also been reported to be equal in both sexes $(7,8)$. NCS has traditionally been believed to occur in slender patients because of the small amount of intra-abdominal fat and the resultant narrow angle between the aorta and SMA $(3,4,9)$. We aimed to confirm this hypothesis by comparing the BMI between patients with NCS and those in the control group. In our study, NCS was more common in females, and the mean BMI was $20.2 \pm 2.7 \mathrm{~kg} / \mathrm{m}^{2}$, which was significantly lower than that in the control group.

As reported in other studies, hematuria was the most common presenting symptom in our study (10). Symptoms related to pelvic vein reflux are often overlooked in patients with NCS. In our study, 6 patients $(20.0 \%)$ had pelvic symptoms. Since we included only 3 patients with duplex ultrasound examination, detailed gonadal vein flow information could not be included in the analysis. Visualization of the gonadal vein reflux in compensated NCS plays a significant role in the diagnosis and helps understand the pathophysiology of the patients' symptoms. Therefore, duplex ultrasound examination of the gonadal vein flow is imperative in patients with NCS.

A previous study on pelvic congestion syndrome showed that dilated ovarian veins were more common in leaner patients (11). On comparing the BMI of $23.82 \mathrm{~kg} / \mathrm{m}^{2}$ reported in a previous study with that of our patients with symptoms of pelvic reflux, our patients showed significantly lower BMI $(\mathrm{p}=.043)$. The support of the surrounding fat tissue might protect the dilation of the ovarian vein. Further research is necessary to determine whether the venous drainage is compensated by the gonadal vein in patients with NCS.

NCS is a radiological diagnosis, although clinical signs and symptoms are manifested (12). Various imaging modalities are used for the diagnosis of NCS; however, the diagnosis is challenging because the diagnostic algorithm and criteria are not well established ( 6 ). The beak sign on CT was suggested as a useful diagnostic tool, with $91.7 \%$ sensitivity and $88.9 \%$ specificity (13). However, in our patients, a positive beak sign on CT showed a high false positive rate, judging by serial $\mathrm{CT}$ scans or additional imaging studies for differential diagnosis. Therefore, it is necessary to consider additional information, including other imaging modalities or relevant symptoms, when making a diagnosis with CTV.

This study has some limitations due to its retrospective nature and small sample size. In addition, we could not obtain detailed information about the gonadal vein reflux. However, the strength of our study is our finding of is a clear correlation between BMI and NCS by comparing the patients with matched controls.

In conclusion, the BMI of patients with NCS was significantly lower than that of the controls. NCS was more common in women, and the most common symptom was gross hematuria.

\section{REFERENCES}

1) Ribeiro FS, Puech-Leão $P$, Zerati $A E$, Nahas WC, David-Neto E, De Luccia N: Prevalence of left renal vein compression (nutcracker phenomenon) signs on computed tomography angiography of healthy individuals. Journal of vascular surgery Venous and lymphatic disorders. 2020.

2) Lamba R, Tanner DT, Sekhon S, McGahan JP, Corwin MT, Lall CG: Multidetector CT of vascular compression syndromes in the abdomen and pelvis. Radiographics. 
2014;34(1):93-115.

3) Kim SH: Doppler US and CT Diagnosis of Nutcracker Syndrome. Korean J Radiol. 2019;20(12):1627-1637.

4) Shin JI, Park JM, Lee JS, Kim MJ: Effect of renal Doppler ultrasound on the detection of nutcracker syndrome in children with hematuria. Eur J Pediatr. 2007;166(5):399-404.

5) Venkatachalam S, Bumpus K, Kapadia SR, Gray B, Lyden $\mathrm{S}$, Shishehbor MH: The nutcracker syndrome. Ann Vasc Surg. 2011;25(8):1154-1164.

6) Ananthan K, Onida S, Davies AH: Nutcracker Syndrome: An Update on Current Diagnostic Criteria and Management Guidelines. European journal of vascular and endovascular surgery : the official journal of the European Society for Vascular Surgery. 2017;53(6):886-894.

7) $\mathrm{He} \mathrm{Y}, \mathrm{Wu} Z$, Chen S, Tian L, Li D, Li M, Jin W, Zhang $\mathrm{H}$ : Nutcracker syndrome--how well do we know it? Urology. 2014;83(1):12-17.

8) Shin JI, Lee JS, Kim MJ: The prevalence, physical characteristics and diagnosis of nutcracker syndrome.
European journal of vascular and endovascular surgery : the official journal of the European Society for Vascular Surgery. 2006;32(3):335-336.

9) Kurklinsky AK, Rooke TW: Nutcracker phenomenon and nutcracker syndrome. Mayo Clin Proc. 2010;85(6):552-559.

10) White JM, Comerota AJ: Venous Compression Syndromes. Vascular and endovascular surgery. 2017;51(3):155-168.

11) Nanavati R, Jasinski P, Adrahtas D, Gasparis A, Labropoulos $\mathrm{N}$ : Correlation between pelvic congestion syndrome and body mass index. J Vasc Surg. 2018;67(2):536-541.

12) Rudloff U, Holmes RJ, Prem JT, Faust GR, Moldwin R, Siegel D: Mesoaortic compression of the left renal vein (nutcracker syndrome): case reports and review of the literature. Ann Vasc Surg. 2006;20(1):120-129.

13) Kim KW, Cho JY, Kim SH, Yoon J-H, Kim DS, Chung JW, Park JH: Diagnostic value of computed tomographic findings of nutcracker syndrome: Correlation with renal venography and renocaval pressure gradients. European Journal of Radiology. 2011;80(3):648-654. 